\title{
PENERAPAN ANALISIS KORELASI KANONIK PADA HUBUNGAN KUALITAS PELAYANAN TERHADAP KEPUASAN NASABAH
}

\author{
Kadek Andrei Prabawa ${ }^{1 \S}$, Ni Luh Putu Suciptawati ${ }^{2 \S}$, Desak Putu Eka Nilakusmawati ${ }^{3}$ \\ ${ }^{1}$ Jurusan Matematika, Fakultas MIPA - Universitas Udayana [Email: andreprabawa46@ gmail.com] \\ ${ }^{2}$ Jurusan Matematika, Fakultas MIPA - Universitas Udayana [Email: putusuciptawati@yahoo.com] \\ ${ }^{3}$ Jurusan Matematika, Fakultas MIPA - Universitas Udayana [Email: nilakusmawati@unud.ac.id] \\ ${ }^{\S}$ Corresponding Author
}

\begin{abstract}
Customer satisfaction is determined by the quality of customer service desired. Service quality of a company are important viewed from a consumer standpoint. The purpose of this study is (1) to determine dominant factors of the service quality by using factor analysis and (2) to determine the relationship among service quality and customer satisfaction by using canonical correlation analysis. The primary data were obtained by distributing questionnaires. The sampling technique used was purposive sampling with the number of respondents as much as 150 customers. Factor analysis showed that the dominant factors in the quality of service is empathy and the competence of company's people with account for data variance as much as 46,156\%. Meanwhile, by using canonical correlation analysis we found that the quality of service and customer satisfaction has close relationship, with the canonical correlation value as much as 0.869 .
\end{abstract}

Keywords: Canonical Correlation Analysis, Customer Satisfaction, Factor Analysis, Service Quality.

\section{PENDAHULUAN}

Analisis peubah ganda merupakan teknik statistik yang digunakan untuk menganalisis data peubah ganda (Hair, dkk. 2010). Analisis faktor dan analisis korelasi kanonik merupakan teknik analisis peubah ganda. Analisis faktor digunakan untuk mencari faktor-faktor dari kualitas pelayanan dan analisis korelasi kanonik digunakan untuk menguji hubungan kualitas pelayanan dengan kepuasan nasabah.

Menurut Zheithaml \& Bitner, (2003) kepuasan nasabah dapat diukur dari empat dimensi yaitu kualitas produk, kualitas jasa, harga, dan biaya. Sedangkan menurut Parasuraman, dkk. (2002) kualitas pelayanan dapat diukur dari lima dimensi yaitu berwujud, kehandalan, daya tanggap, jaminan, dan kepedulian.

Kualitas pelayanan dalam perusahaan jasa merupakan hal yang penting untuk menentukan kepuasan konsumen. Sebagai contoh bisnis yang bergerak dalam bidang jasa adalah koperasi.

Tujuan dari penelitian ini yaitu mengetahui faktor yang dominan dalam kualitas pelayanan di Koperasi Arry Sedana Artha dan mengetahui hubungan kualitas pelayanan terhadap kepuasan nasabah di Koperasi Arry Sedana Artha.

\section{Tinjauan Pustaka}

\subsection{Kualitas Pelayanan dan Kepuasan Nasabah}

Menurut Parasuraman, dkk. (2002) kualitas pelayanan sebagai hasil persepsi dari perbandingan antara harapan pelanggan dengan kinerja aktual pelayanan. Kualitas pelayanan dapat diukur dengan menggunakan lima dimensi yaitu berwujud, kehandalan, daya tanggap, jaminan, dan kepedulian.

Menurut Kotler (2005) menyatakan bahwa kepuasan nasabah adalah perasaan senang atau tidak senang seseorang ketika membandingkan antara hasil produk yang dipikirkan terhadap hasil yang diharapkan. Kepuasan nasabah dapat diukur dari empat faktor menurut Zheithaml \& Bitner (2003) yaitu kualitas produk, kualitas jasa, harga dan biaya 


\subsection{Analisis Faktor}

Analisis faktor merupakan teknik analisis peubah ganda yang digunakan untuk mengetahui faktor-faktor yang melandasi dan menunjukkan saling keterkaitan diantara peubah. Tujuan utama dari analisis faktor adalah menemukan cara untuk mengambarkan informasi yang terkandung dalam jumlah dari variabel asli kedalam himpunan baru yang lebih kecil (Hair, dkk. 2010).

Misalkan terdapat $\mathrm{p}$ indikator dan $\mathrm{m}$ faktor, maka dapat dibuat model sebagai berikut:

$$
\begin{array}{cc}
X_{1}= & c_{11} F_{1}+c_{12} F_{2}+\cdots+c_{1 m} F_{m}+\varepsilon_{1} \\
X_{2}= & c_{21} F_{1}+c_{22} F_{2}+\cdots+c_{2 m} F_{m}+\varepsilon_{2} \\
\vdots & \vdots \\
X_{p}= & c_{p 1} F_{1}+c_{p 2} F_{2}+\cdots+c_{p m} F_{m}+\varepsilon_{p}
\end{array}
$$

dengan:

$X_{i}=$ indikator atau variabel ke- $i, i=1,2, \ldots, p$

$F_{j}=$ faktor ke-j, $j=1,2, \ldots, m$

$c_{i j}=$ bobot (loading) dari indikator ke- $i$ pada

faktor ke-j, $i=1,2, \ldots, p$ dan $j=1,2, \ldots, m$

$\varepsilon_{i}=$ galat (error)

Pengujian yang dilakukan untuk melihat apakah data yang diperoleh layak untuk diolah dengan menggunakan analisis faktor adalah dengan melakukan tiga uji (Hair, dkk. 2010):

1. Kaiser Meyer Olkin (KMO) digunakan untuk mengukur derajat korelasi antar indikator. Nilai KMO agar analisis faktor tepat digunakan adalah lebih besar dari 0,5.

2. Uji Bartlett digunakan untuk menguji korelasi antar indikator. Pada uji Bartlett jika nilai signifikansi kurang dari taraf nyata $(\alpha=0,05)$ maka analisis faktor tepat digunakan.

3. Uji Measure of Sampling Adequency (MSA) digunakan untuk mengukur kelayakan sebuah indikator atau variabel disertakan dalam analisis faktor. Indikator yang layak digunakan dalam analisis faktor adalah indikator yang memiliki nilai anti-image $\geq 0,6$.

Untuk menentukan jumlah faktor digunakan nilai akar ciri (eigen value). Faktor yang dianggap nyata (signifikan) adalah yang memiliki nilai akar ciri lebih dari satu $(\lambda>1)$. Nilai akar ciri menunjukkan besarnya sumbangan dari faktor terhadap varian seluruh peubah asli. Selanjutnya rotasi faktor dilakukan untuk mengetahui indikator yang masuk dalam suatu faktor. Dalam rotasi faktor ada dua metode yaitu metode orthogonal rotation dan metode oblique rotation.

1. Metode orthogonal rotation merupakan metode rotasi yang menghasilkan faktorfaktor yang saling ortogonal. Rotasi ortogonal menghasilkan faktor-faktor yang tidak berkorelasi satu sama lain. Rotasi ortogonal dibagi menjadi tiga yaitu varimax, equimax dan quartimax.

2. Metode oblique rotation merupakan metode rotasi yang tidak menghasilkan faktor-faktor yang saling ortogonal. Oblique rotation menghasilkan faktor-faktor yang saling berkorelasi satu sama lain. Oblique rotation dibagi menjadi tiga yaitu oblimin, promax dan orthoblique.

\subsection{Analisis Korelasi Kanonik}

Analisis korelasi kanonik merupakan salah satu teknik analisis peubah ganda yang sering digunakan peneliti ketika menguji hubungan (korelasi) antara beberapa beubah dependen dengan beberapa peubah independen. Secara matematis didefinisikan hubungan antara sekelompok variabel dependen $\left(y_{1}, y_{2}, \ldots, y_{p}\right)$ dengan sekelompok variabel independen $\left(x_{1}, x_{2}, \ldots, x_{q}\right)$ (Hair et. al, 2010). Tujuan dari analisis korelasi kanonik adalah mengukur tingkat keeratan hubungan antara sekelompok peubah dependen dengan sekelompok peubah independen dan menguraikan struktur hubungan di dalam kelompok peubah dependen maupun dalam kelompok peubah independen.

Jika $U$ adalah indikator yang baru berasal dari kombinasi linear $p$ indikator pertama dan $\mathrm{W}$ adalah indikator baru yang berasal dari kombinasi linear $q$ indikator kedua (Hair, dkk. 1995), maka:

$$
\begin{gathered}
U=\left[\underline{a}^{\prime}, \underline{0}\right] X^{*} \\
W=\left[\underline{0}, \underline{b}^{\prime}\right] X^{*}
\end{gathered}
$$


dimana: $X^{*}=\left[X_{1}, X_{2}, \ldots, X_{p}, Z_{1}, Z_{2}, \ldots, Z_{q}\right]$

Skor komponen menjadi:

$$
\begin{aligned}
& \underline{u}=x \underline{a} \rightarrow u_{i}=\sum_{j=1}^{p} a_{j} x_{i j} ; i=1,2, \ldots, n \\
& \underline{w}=z \underline{b} \rightarrow v_{i}=\sum_{j=i}^{p} b_{j} z_{i j} \quad ; i=1,2, \ldots, n
\end{aligned}
$$

Korelasi antara indikator U dan W adalah:

$$
\begin{aligned}
& \operatorname{Cor}(U, W)=\frac{\operatorname{Cov}(U, W)}{\sqrt{\operatorname{Var}(U) \operatorname{Var}(W)}} \\
& =\frac{\operatorname{Cov}\left(\left[\underline{a}^{\prime}, \underline{0}\right] X^{*},\left[\underline{0}, \underline{b}^{\prime}\right] X^{*}\right)}{\sqrt{\operatorname{Var}(U) \operatorname{Var}(W)}} \\
& =\frac{\left[\underline{a}^{\prime}, \underline{0}\right] \operatorname{cov}\left(X^{*}\right)[\underline{0} \underline{b}]}{\sqrt{\left(\frac{1}{n} \underline{a}^{\prime} X^{\prime} X \underline{a}\right)\left(\frac{1}{n} \underline{b}^{\prime} Z^{\prime} Z \underline{b}\right)}} \\
& =\frac{\left[\underline{a}^{\prime}, \underline{0}\right] \frac{1}{n}\left[\begin{array}{ll}
X^{\prime} X & X^{\prime} Z \\
Z^{\prime} X & Z^{\prime} Z
\end{array}\right]\left[\begin{array}{l}
\underline{0} \\
\underline{b}
\end{array}\right]}{\frac{1}{n} \sqrt{\left(\underline{a}^{\prime} X^{\prime} X \underline{a}\right)\left(\underline{b}^{\prime} Z^{\prime} Z \underline{b}\right)}} \\
& =\frac{\underline{a^{\prime} X^{\prime} Z \underline{b}}}{\sqrt{\left(\underline{a}^{\prime} X^{\prime} X \underline{a}\right)\left(\underline{b}^{\prime} Z^{\prime} Z \underline{b}\right)}}
\end{aligned}
$$

Interpretasi yang dilakukan dalam analisis korelasi kanonik ada tiga metode yaitu (Hair, dkk. 2010):

\section{Canonical weight}

Canonical weight mengambarkan besarnya kontribusi peubah asal dalam peubah kanoniknya dalam satu kumpulan. Peubah yang memiliki bobot yang berlawanan tanda memiliki hubungan kebalikan dengan peubah kanonik lainnya dan yang memiliki tanda yang sama memiliki hubungan searah. Kontribusi peubah asal dinilai tidak akurat dalam merefleksikan hubungan antar peubah karena rentan terhadap adanya mutikolinearitas.

\section{Canonical loading}

Canonical loading disebut sebagai korelasi struktur, mengukur korelasi linear yang sederhana antara data observasi pada peubah dependen atau independen dengan kumpulan peubah kanoniknya. Peubah asal yang memiliki nilai beban kanonik lebih besar dari 0,5 dikatakan memiliki peranan besar dalam kumpulan peubahnya, sedangkan tanda beban kanonik menunjukkan arah hubungannya.

\section{Canonical cross loading}

Canonical cross loading digunakan untuk melihat korelasi antar peubah asal dalam satu kumpulan dengan peubah kanonik pada kumpulan yang lain. Semakin besar nilai loading maka semakin erat hubungan antara kedua kumpulan peubah

\section{METODE PENELITIAN}

Penelitian ini dilaksanakan di Koperasi Arry Sedana Artha yang bertempat di Jalan Gunung Batok III, Perum Munang Maning, Denpasar Barat. Waktu penelitian dilakukan pada bulan September-November 2016.

Populasi dalam penelitian ini adalah seluruh nasabah di Koperasi Arry Sedana Artha yang masih aktif dalam melakukan transaksi. Teknik sampling yang digunakan adalah purposive sampling, yaitu menentukan lokasi sampel secara sengaja dengan dasar pertimbangan bahwa nasabah yang tinggal di Denpasar lebih banyak dari daerah lain. Jumlah sampel yang diambil sebanyak 150 orang.

Data yang digunakan adalah data primer, yaitu data yang diperoleh melalui kegiatan penelitian langsung ke lokasi penelitian. Untuk mengumpulkan data primer maka teknik yang digunakan yaitu dengan menyebar kuesioner kepada semua nasabah Koperasi Arry Sedana Artha yang tinggal di Denpasar.

Variabel yang digunakan dalam penelitian ini adalah kepuasan nasabah (Y) meliputi kualitas produk $\left(y_{1}\right)$, kualitas jasa $\left(y_{2}\right)$, harga $\left(y_{3}\right)$, biaya $\left(y_{4}\right)$ dan kualitas pelayanan $(\mathrm{X})$ meliputi berwujud $\left(x_{1}\right)$, kehandalan $\left(x_{2}\right)$, daya tanggap $\left(x_{3}\right)$, jaminan $\left(x_{4}\right)$, kepedulian $\left(x_{5}\right)$.

Uji validitas digunakan untuk mengetahui valid atau tidaknya suatu item pernyataan. Suatu item dikatakan valid jika memiliki nilai koefisien korelasi lebih dari $r_{\text {tabel. }}$ Uji reliabilitas digunakan untuk mengukur suatu kuesioner yang merupakan indikator dari variabel. Kuesioner yang digunakan bersifat reliabel apabila nilai Alpha Cronbach $(\alpha)$ lebih besar atau sama dengan 0,6 (Hair, dkk. 2010). 
Langkah-langkah yang dilakukan dalam menganalisis data dari penelitian ini yaitu:

1. Analisis Faktor

a. Melakukan uji KMO, Bartlett dan MSA untuk melihat data yang diperoleh dari indikator kualitas pelayanan layak untuk diolah.

b. Menentukan jumlah faktor dengan melihat nilai akar ciri (eigen value). Faktor yang diambil apabila memiliki nilai akar ciri yang lebih dari satu.

c. Melakukan rotasi faktor untuk mengetahui indikator yang masuk dalam suatu faktor. Metode rotasi faktor yang digunakan adalah metode promax, yaitu bagian dari meotde oblique rotation.

d. Menentukan skor faktor untuk digunakan dalam analisis korelasi kanonik.

2. Analisis Korelasi Kanonik

a. Melakukan uji signifikansi nilai korelasi kanonik terhadap kualitas pelayanan dengan kepuasan nasabah dan tiap faktor kualitas pelayanan dengan tiap faktor kepuasan nasabah. Korelasi kanonik yang signifikan jika nilai $P_{\text {value }}<0,05$ (taraf nyata).

b. Menginterpretasikan hasil analisis korelasi kanonik dengan melihat nilai korelasi kanonik.

\section{HASIL DAN PEMBAHASAN}

\subsection{Uji Validitas dan Reliabilitas Kuesioner}

Uji validitas dan reliabilitas kuesioner dilakukan dengan menyebarkan kuesioner kepada 30 nasabah Koperasi Arry Sedana Artha. Uji validitas dilakukan dengan mencari nilai koefisien korelasi kemudian dibandingkan dengan $r_{\text {tabel }}$ dengan $n=30$ dan $\mathrm{db}=28$ serta taraf nyata 0,05 yaitu 0,361 . Uji reliabilits dapat dilihat dari nilai Alpha Cronbach $(\alpha)$. Kuesioner yang bersifat reliabel apabila nilai $\alpha$ lebih besar atau sama dengan 0,6 (Hair, dkk. 2010).
Tabel 1. Uji Validitas dan Reliabilitas dari Kualitas Pelayanan

\begin{tabular}{|c|c|c|}
\hline Item & $\begin{array}{c}\text { Koefisien } \\
\text { Korelasi }\end{array}$ & Ket. \\
\hline $\begin{array}{l}\mathrm{X}_{11} \text { (Keadaan gedung dan } \\
\text { lingkungan) }\end{array}$ & 0,518 & Valid \\
\hline $\mathrm{X}_{12}$ (Peralatan dan teknologi) & 0,614 & Valid \\
\hline $\mathrm{X}_{13}$ (Penampilan karyawan) & 0,826 & Valid \\
\hline $\begin{array}{c}\mathrm{X}_{21} \text { (Menangani masalah } \\
\text { dalam bertransaksi) }\end{array}$ & 0,746 & Valid \\
\hline $\begin{array}{l}\mathrm{X}_{22} \text { (Menjawab pertanyaan } \\
\text { nasabah) }\end{array}$ & 0,787 & Valid \\
\hline $\begin{array}{l}\mathrm{X}_{31} \text { (Membantu dan } \\
\text { merespon nasabah) }\end{array}$ & 0,723 & Valid \\
\hline $\mathrm{X}_{32}$ (Bekerja sama) & 0,813 & Valid \\
\hline $\begin{array}{c}\mathrm{X}_{41} \text { (Rasa aman dalam } \\
\text { bertransaksi) }\end{array}$ & 0,727 & Valid \\
\hline $\mathrm{X}_{42}$ (Profesional) & 0,742 & Valid \\
\hline $\mathrm{X}_{43}($ Sopan dan santun $)$ & 0,597 & Valid \\
\hline $\mathrm{X}_{44}$ (Pengetahuan yang luas) & 0,653 & Valid \\
\hline $\begin{array}{l}\mathrm{X}_{51} \text { (Menangani keluhan } \\
\text { nasabah) }\end{array}$ & 0,823 & Valid \\
\hline $\begin{array}{l}\mathrm{X}_{52} \text { (Memahami kebutuhan } \\
\text { nasabah) }\end{array}$ & 0,632 & Valid \\
\hline \multicolumn{3}{|c|}{ Kualitas Pelayanan; $\alpha=\mathbf{0 , 9 3 2}$} \\
\hline
\end{tabular}

Sumber: Data primer yang diolah (2016)

Tabel 2. Uji Validitas dan Reliabilitas dari Kepuasan Nasabah

\begin{tabular}{|l|c|c|}
\hline \multicolumn{1}{|c|}{ Item } & $\begin{array}{c}\text { Koefisien } \\
\text { Korelasi }\end{array}$ & Ket. \\
\hline$Y_{11}$ (Bunga tabungan) & 0,459 & Valid \\
\hline$Y_{12}$ (Penerimaan uang) & 0,459 & Valid \\
\hline Dimensi Kualitas Produk; $\boldsymbol{\alpha}=\mathbf{0 , 6 2 9}$ \\
\hline $\begin{array}{l}Y_{21} \text { (Keadaan lingkungan } \\
\text { dan fasilitas) }\end{array}$ & 0,437 & Valid \\
\hline$Y_{22}$ (Penampilan karyawan) & 0,456 & Valid \\
\hline$Y_{23}$ (Melayani nasabah) & 0,644 & Valid \\
\hline $\begin{array}{c}\text { Y } \\
\text { nasabah) }\end{array}$ & 0,659 & Valid \\
\hline$Y_{25}$ (Kepercayaan) & 0,456 & Valid \\
\hline$Y_{26}$ (Pelayanan sama) & 0,565 & Valid \\
\hline Dimensi Kualitas Jasa; $\boldsymbol{\alpha}=\mathbf{0 , 7 8 5}$ & Valid \\
\hline$Y_{31}$ (3 tipe angsuran) & 0,472 & Valid \\
\hline$Y_{32}$ (Bunga angsuran) & 0,472 \\
\hline Dimensi Harga; $\boldsymbol{\alpha}=\mathbf{0 , 6 3 2}$ \\
\hline$Y_{41}$ (Biaya tahunan) & 0,828 & Valid \\
\hline$Y_{43}$ (Transaksi di tempat) & 0,828 & Valid \\
\hline Dimensi Biaya; $\boldsymbol{\alpha}=\mathbf{0 , 9 0 6}$ \\
\hline
\end{tabular}

Sumber: Data primer yang diolah (2016) 
Item-item pada Tabel 1 dan Tabel 2 memiliki nilai koefisien korelasi lebih besar dari 0,361 sehingga item-item pernyataan dikatakan valid. Kuesioner yang dirancang dikatakan reliabel karena nilai $\alpha$ yang diperoleh lebih dari 0,6 .

\subsection{Uji Kelayakan Data}

Analisis faktor tepat dan layak digunakan apabila peubah-peubah tersebut harus berkorelasi. Matriks korelasi yang diperoleh dari masing-masing item yang merupakan peubah dalam analisis faktor yang menunjukkan bahwa peubah-peubah tersebut saling berkorelasi, karena nilai determinan mendekati 0 yaitu 0,001.

Pengujian selanjutnya yang dilakukan untuk melihat apakah data yang diperoleh layak untuk diolah dengan menggunakan analisis faktor melakukan uji KMO dan uji Bartlett. Jika nilai KMO di atas 0,5 dan uji Bartlett dengan signifikansi kurang dari taraf nyata 0,05 maka analisis faktor tepat digunakan (Hair, dkk. 2010). Data dalam penelitian ini memiliki nilai KMO sebesar 0,821 dan uji Bartlett nilai signifikansinya kurang dari 0,05 (Tabel 3), hal ini menunjukkan bahwa analisis faktor tepat digunakan.

Tabel 3. Uji KMO dan Uji Bartlett

\begin{tabular}{|l|l|}
\hline \multicolumn{1}{|c|}{ Uji } & Nilai \\
\hline KMO & 0,821 \\
\hline Bartlett (Sig.) & 0,00 \\
\hline
\end{tabular}

Sumber: Data primer yang diolah (2016)

Selanjutnya, dilakukan uji MSA untuk masing-masing item. Pada Tabel 4 menunjukkan bahwa tidak ada item yang memiliki nilai MSA kurang dari 0,6. Nilai tersebut mengindikasikan item-item tersebut mampu menjelaskan faktorfaktor yang memengaruhi kualitas pelayanan.

Tabel 4. Nilai MSA

\begin{tabular}{|c|c|}
\hline Item & Nilai MSA \\
\hline $\mathrm{X}_{11}$ & 0,809 \\
\hline $\mathrm{X}_{12}$ & 0,802 \\
\hline $\mathrm{X}_{13}$ & 0,781 \\
\hline $\mathrm{X}_{21}$ & 0,874 \\
\hline $\mathrm{X}_{22}$ & 0,853 \\
\hline $\mathrm{X}_{31}$ & 0,800 \\
\hline $\mathrm{X}_{32}$ & 0,846 \\
\hline
\end{tabular}

\begin{tabular}{|l|l|}
\hline $\mathrm{X}_{41}$ & 0,854 \\
\hline $\mathrm{X}_{42}$ & 0,825 \\
\hline $\mathrm{X}_{43}$ & 0,805 \\
\hline $\mathrm{X}_{44}$ & 0,751 \\
\hline $\mathrm{X}_{51}$ & 0,893 \\
\hline $\mathrm{X}_{52}$ & 0,759 \\
\hline
\end{tabular}

Sumber: Data primer yang diolah (2016)

\subsection{Komunalitas}

Komunalitas digunakan untuk menentukan seberapa besar suatu item dapat menjelaskan suatu faktor. Jika suatu item memiliki nilai komunalitas lebih dari 0,5 maka dapat dikatakan bahwa item tersebut dapat menjelaskan faktor. Begitu juga sebaliknya jika suatu item memiliki nilai komunalitas kurang dari 0,5 maka dapat dikatakan bahwa item tersebut tidak dapat menjelaskan faktor dan item tersebut harus dikeluarkan dalam analisis selanjutnya (Hair, dkk. 2010). Tabel 4.7 menunjukkan nilai komunalitas.

Tabel 5. Nilai Komunalitas

\begin{tabular}{|c|c|}
\hline Item & Nilai Komunalitas \\
\hline$X_{11}$ & 0,654 \\
\hline$X_{12}$ & 0,791 \\
\hline$X_{13}$ & 0,817 \\
\hline$X_{21}$ & 0,579 \\
\hline$X_{22}$ & 0,684 \\
\hline$X_{31}$ & 0,783 \\
\hline$X_{32}$ & 0,699 \\
\hline$X_{41}$ & 0,761 \\
\hline$X_{42}$ & 0,421 \\
\hline$X_{43}$ & 0,527 \\
\hline$X_{44}$ & 0,732 \\
\hline$X_{51}$ & 0,750 \\
\hline$X_{52}$ & 0,768 \\
\hline$X_{11}$ Setah Item $\mathbf{X}_{42}$ Dikeluarkan \\
\hline$X_{11}$ & 0,661 \\
\hline$X_{12}$ & 0,798 \\
\hline$X_{13}$ & 0,822 \\
\hline$X_{21}$ & 0,613 \\
\hline$X_{22}$ & 0,701 \\
\hline$X_{31}$ & 0,787 \\
\hline$X_{32}$ & 0,661 \\
\hline$X_{41}$ & 0,757 \\
\hline$X_{43}$ & 0,539 \\
\hline$X_{44}$ & 0,744 \\
\hline$X_{51}$ & 0,750 \\
\hline$X_{52}$ & 0,763 \\
\hline
\end{tabular}

Sumber: Data primer yang diolah (2016)

Tabel 5 menunjukkan bahwa item $\mathrm{X}_{42}$ memiliki nilai komunalitas 0,421 lebih kecil dari 
0,5. sehingga diputuskan untuk mengeluarkan item $\mathrm{X}_{42}$. Setelah item $\mathrm{X}_{42}$ dikeluarkan, adanya perubahan nilai komunalitas pada item-item yang lain.

\subsection{Jumlah Faktor}

Untuk mengekstraksi jumlah faktor digunakan nilai akar ciri. Faktor yang dianggap signifikan adalah yang memiliki nilai akar ciri lebih dari satu $(\lambda>1)$. Nilai akar ciri yang dihasilkan dapat dilihat pada Tabel 6 .

Tabel 6. Nilai Akar Ciri Faktor

\begin{tabular}{|c|c|c|c|}
\hline Faktor & $\begin{array}{c}\text { Nilai } \\
\text { Akar } \\
\text { Ciri }\end{array}$ & $\begin{array}{c}\text { Persentase } \\
\text { Variansi }\end{array}$ & $\begin{array}{c}\text { Persentase } \\
\text { Komulatif }\end{array}$ \\
\hline 1 & 5,539 & 46,156 & 46,156 \\
\hline 2 & 1,893 & 15,779 & 61,935 \\
\hline 3 & 1,164 & 9,696 & 71,631 \\
\hline 4 & 0,697 & 5,809 & 77,441 \\
\hline 5 & 0,652 & 5,434 & 82,875 \\
\hline 6 & 0,520 & 4,336 & 87,211 \\
\hline 7 & 0,406 & 3,380 & 90,591 \\
\hline 8 & 0,291 & 2,428 & 93,019 \\
\hline 9 & 0,278 & 2,319 & 95,338 \\
\hline 10 & 0,217 & 1,812 & 97,150 \\
\hline 11 & 0,185 & 1,545 & 98,694 \\
\hline 12 & 0,157 & 1,306 & 100,000 \\
\hline
\end{tabular}

Sumber: Data primer yang diolah (2016)

Tabel 6 menunjukkan bahwa tiga komponen utama yang memiliki nilai akar ciri lebih besar dari satu. Hal ini menunjukkan bahwa jumlah faktor yang memengaruhi kualitas pelayanan sebanyak tiga faktor. Tiga komponen utama ini secara bersama mampu menerangkan keragaman kualitas pelayanan sebesar $71,631 \%$.

\subsection{Rotasi Faktor}

Rotasi faktor yang digunakan dalam penelitian ini adalah rotasi promax, yaitu bagian dari metode oblique rotation dengan asumsi bahwa faktor-faktor kualitas pelayanan saling berkorelasi satu sama lain. Hasil rotasi faktor dapat dilihat pada tabel 7 .
Tabel 7. Hasil Rotasi Faktor

\begin{tabular}{|c|c|c|c|}
\hline \multirow{2}{*}{ Item } & \multicolumn{3}{|c|}{ Komponen } \\
\cline { 2 - 4 } & $\mathbf{1}$ & $\mathbf{2}$ & $\mathbf{3}$ \\
\hline $\mathrm{X}_{52}$ & $\mathbf{0 , 8 6 5}$ & 0,344 & 0,187 \\
\hline $\mathrm{X}_{51}$ & $\mathbf{0 , 8 4 1}$ & 0,485 & 0,179 \\
\hline $\mathrm{X}_{44}$ & $\mathbf{0 , 8 3 3}$ & 0,269 & 0,378 \\
\hline $\mathrm{X}_{22}$ & $\mathbf{0 , 8 3 0}$ & 0,453 & 0,383 \\
\hline $\mathrm{X}_{31}$ & 0,437 & $\mathbf{0 , 8 7 7}$ & 0,348 \\
\hline $\mathrm{X}_{41}$ & 0,502 & $\mathbf{0 , 8 6 2}$ & 0,424 \\
\hline $\mathrm{X}_{11}$ & 0,192 & $\mathbf{0 , 7 8 5}$ & 0,436 \\
\hline $\mathrm{X}_{21}$ & 0,499 & $\mathbf{0 , 7 0 0}$ & 0,632 \\
\hline $\mathrm{X}_{32}$ & 0,508 & $\mathbf{0 , 6 9 7}$ & 0,693 \\
\hline $\mathrm{X}_{13}$ & 0,344 & 0,439 & $\mathbf{0 , 9 0 5}$ \\
\hline $\mathrm{X}_{12}$ & 0,214 & 0,370 & $\mathbf{0 , 8 8 5}$ \\
\hline $\mathrm{X}_{43}$ & 0,213 & 0,596 & $\mathbf{0 , 6 5 8}$ \\
\hline
\end{tabular}

Sumber: Data primer yang diolah (2016)

\subsection{Interpretasi Faktor}

Interpretasi faktor dilakukan dengan cara mengelompokkan indikator yang memiliki faktor pembobot minimal 0,45 karena sampel dalam penelitian ini berukuran 150. Variabel yang memiliki faktor pembobot kurang dari 0,45 dikeluarkan dari model. Berdasarkan tabel 7 dapat dilihat bahwa tidak ada variabel yang memeiliki faktor pembobot kurang dari atau sama dengan 0,45.

Berdasarkan hasil rotasi promax dapat dilihat bahwa ada tiga faktor baru. Tiga faktor baru dalam penelitian ini masing-masing diberi nama baru sesuai dengan pengelompokan variabel pada faktor tersebut.

1. Faktor pertama disebut dengan faktor perhatian dan kompetensi. Faktor ini adalah faktor yang paling memengaruhi kualitas pelayanan di Koperasi Arry Sedana Artha karena memiliki nilai akar ciri paling tinggi yaitu 5,539 dan mampu menjelaskan keragaman sebesar 46,156\%. Menurut Parasuraman, dkk. (2002) kualitas pelayanan dapat diukur dengan sepuluh faktor. Faktor perhatian dan kompetensi merupakan bagian dari sepuluh faktor tersebut yang artinya kemampuan karyawan memberikan perhatian yang bersifat pribadi, memahami kebutuhan pelanggan dan juga memiliki keterampilan atau pengetahuan yang tinggi. 
Nilai loading factor terbesar dalam faktor ini dimiliki oleh indikator Karyawan Koperasi Arry Sedana Artha memahami kebutuhan nasabah yaitu sebesar 0,865 .

2. Faktor kedua disebut dengan faktor daya tanggap dan kepastian. Faktor ini memiliki nilai akar ciri 1.893 dan mampu menjelaskan keragaman sebesar $15.779 \%$. Menurut Zheithaml \& Bitner (2003) kualitas pelayanan dapat diukur dengan faktor daya tanggap dan kepastian yaitu kemampuan karyawan membantu dan memberikan pelayanan dengan cepat, tanggap, dan adanya perasaan aman bagi nasabah baik dalam bertransaksi dan keadaan lingkungan. Pada faktor ini terdapat beberapa komponen, yaitu komunikasi, keamanan, kredibilitas, dan pengetahuan. Nilai loading factor terbesar dalam faktor ini dimiliki oleh indikator Karyawan Koperasi Arry Sedana Artha selalu siap untuk membantu dan merespon permintaan nasabah yaitu sebesar 0,877 .

3. Faktor 3 disebut dengan faktor bukti fisik. Faktor ini memiliki nilai akar ciri 1,164 dan mampu menjelaskan keragaman sebesar 9,696\%. Parasuraman, dkk. (2002) mengatakan bahwa kualitas pelayanan dapat diukur dengan lima faktor. Salah satu faktor tersebut adalah faktor bukti fisik yaitu sebagai fasilitas yang dapat dilihat dan digunakan perusahaan untuk memenuhi kepuasan nasabah, seperti penampilan karyawan, peralatan dan teknologi, dan lainlain. Nilai loading factor terbesar dalam faktor ini dimiliki oleh indikator Karyawan Koperasi Arry Sedana Artha berpenampilan bersih dan rapi yaitu sebesar 0,905 .

\subsection{Uji Signifikansi Nilai Korelai Kanonik}

Korelasi kanonik untuk faktor-faktor kualitas pelayanan terhadap kepuasan nasabah yang dianalisis adalah skor faktor dari tiga faktor kualitas pelayanan yang diperoleh dari analisis faktor dengan empat dimensi kepuasan nasabah. Kemudian dilakukan uji signifikansi terhadap nilai korelasi yang diperoleh dengan membandingkan $p$-value dengan taraf nyata 0,05 . Korelasi kanonik dikatakan signifikan apabila $p$-value lebih kecil dari 0,05 . Nilai-nilai korelasi kanonik dapat dilihat pada Tabel 8 sampai dengan Tabel 12.

Tabel 8. Uji Signifikansi Nilai Korelasi FaktorFaktor Kualitas Pelayanan dengan Kepuasan Nasabah

\begin{tabular}{|lll|c|c|}
\hline \multicolumn{2}{|c|}{ Hubungan } & Nilai & p-value \\
\hline $\begin{array}{l}\text { Perhatian dan } \\
\text { Kompetensi }\end{array}$ & $\rightarrow$ & $\begin{array}{l}\text { Kepuasan } \\
\text { nasabah }\end{array}$ & 0,673 & 0,00 \\
\hline $\begin{array}{l}\text { Daya Tanggap } \\
\text { dan Kepastian }\end{array} \rightarrow \begin{array}{c}\text { Kepuasan } \\
\text { nasabah }\end{array}$ & 0,845 & 0,00 \\
\hline Bukti Fisik $\rightarrow$ & $\begin{array}{l}\text { Kepuasan } \\
\text { nasabah }\end{array}$ & 0,806 & 0,00 \\
\hline $\begin{array}{l}\text { Kualitas } \\
\text { Pelayanan }\end{array} \rightarrow \begin{array}{c}\text { Kepuasan } \\
\text { nasabah }\end{array}$ & $\mathbf{0 , 8 6 9}$ & $\mathbf{0 , 0 0}$ \\
\hline
\end{tabular}

Sumber: Data primer yang diolah (2016)

Hasil uji signifikansi untuk nilai korelasi pada Tabel 8 menunjukkan bahwa ketiga faktor kualitas pelayanan signifikan terhadap kepuasan nasabah. Hal ini menunjukkan bahwa faktorfaktor kepuasan nasabah secara nyata memberi pengaruh terhadap kepuasan nasabah. Nilai korelasi terbesar adalah faktor daya tanggap dan kepastian dengan kepuasan nasabah yaitu sebesar 0,845, artinya karyawan koperasi cepat dan tanggap dalam melayani nasabah dan timbul perasaan aman bagi nasabah dapat membuat nasabah merasa puas. Selain itu dapat dilihat bahwa kualitas pelayanan memiliki korelasi yang signifikan dengan kepuasan nasabah sebesar 0,869, artinya kualitas pelayanan yang baik memberikan dampak yang baik juga terhadap kepuasan nasabah.

Tabel 9. Uji Signifikansi Nilai Korelasi FaktorFaktor Kualitas Pelayanan dengan Dimensi Kualitas Produk

\begin{tabular}{|lll|c|c|}
\hline \multicolumn{2}{|c|}{ Hubungan } & Nilai & p-value \\
\hline $\begin{array}{l}\text { Perhatian dan } \\
\text { Kompetensi }\end{array}$ & $\rightarrow$ & $\begin{array}{l}\text { Kualitas } \\
\text { produk }\end{array}$ & 0,378 & 0,00 \\
\hline $\begin{array}{l}\text { Daya Tanggap } \\
\text { dan Kepastian }\end{array} \rightarrow \begin{array}{l}\text { Kualitas } \\
\text { produk }\end{array}$ & 0,644 & 0,00 \\
\hline Bukti Fisik $\rightarrow$ & $\begin{array}{l}\text { Kualitas } \\
\text { produk }\end{array}$ & 0,606 & 0,00 \\
\hline
\end{tabular}

Sumber: Data primer yang diolah (2016)

Hasil uji signifikansi untuk nilai korelasi 
pada Tabel 9 menunjukkan bahwa ketiga faktor kualitas pelayanan memiliki korelasi yang signifikan dengan indikator kualitas produk. Artinya setiap faktor kualitas pelayanan memberikan pengaruh yang nyata terhadap indikator kualitas produk. Faktor yang memberikan korelasi terbesar pada indikator kualitas produk adalah faktor daya tanggap dan kepastian yaitu sebesar 0,644 , artinya nasabah merasa puas karena uang yang dipinjam cepat diterima oleh nasabah dan aman dalam melakukan transaksi. Secara umum kualitas pelayanan memberikan hubungan yang baik terhadap kepuasan nasabah dalam halnya dimensi kualitas produk.

Tabel 10. Uji Signifikansi Nilai Korelasi Faktor-Faktor Kualitas Pelayanan dengan Dimensi Kualitas Jasa

\begin{tabular}{|ll|l|c|}
\hline \multicolumn{2}{|c|}{ Hubungan } & Nilai & p-value \\
\hline $\begin{array}{l}\text { Perhatian dan } \\
\text { Kompetensi }\end{array} \rightarrow \begin{array}{l}\text { Kualitas } \\
\text { jasa }\end{array}$ & 0,597 & 0,00 \\
\hline $\begin{array}{l}\text { Daya Tanggap } \\
\text { dan Kepastian }\end{array} \rightarrow \begin{array}{l}\text { Kualitas } \\
\text { jasa }\end{array}$ & 0,834 & 0,00 \\
\hline Bukti Fisik $\rightarrow \quad \begin{array}{l}\text { Kualitas } \\
\text { jasa }\end{array}$ & 0,705 & 0,00 \\
\hline
\end{tabular}

Sumber: Data primer yang diolah (2016)

Hasil uji signifikansi untuk nilai korelasi pada Tabel 10 menunjukkan bahwa ketiga faktor kualitas pelayanan memiliki korelasi yang signifikan dengan indikator kualitas jasa. Artinya setiap faktor kualitas pelayanan memberikan pengaruh yang nyata terhadap indikator kualitas jasa. Faktor yang memberikan korelasi terbesar pada indikator kualitas jasa adalah faktor daya tanggap dan kepastian yaitu sebesar 0,834 . Secara umum kualitas pelayanan memberikan hubungan yang baik terhadap kepuasan nasabah dalam halnya dimensi kualitas jasa.

Tabel 11. Uji Signifikansi Nilai Korelasi FaktorFaktor Kualitas Pelayanan dengan Dimensi Harga

\begin{tabular}{|lll|c|c|}
\hline \multicolumn{2}{|c|}{ Hubungan } & Nilai & p-value \\
\hline $\begin{array}{l}\text { Perhatian dan } \\
\text { Kompetensi }\end{array}$ & Harga & 0,511 & 0,00 \\
\hline $\begin{array}{l}\text { Daya Tanggap } \\
\text { dan Kepastian }\end{array} \rightarrow$ Harga & 0,441 & 0,00 \\
\hline Bukti Fisik $\rightarrow$ Harga & 0,620 & 0,00 \\
\hline
\end{tabular}

Sumber: Data primer yang diolah (2016)
Hasil uji signifikansi untuk nilai korelasi pada Tabel 11 menunjukkan bahwa ketiga faktor kualitas pelayanan memiliki korelasi yang signifikan dengan indikator harga. Artinya setiap faktor kualitas pelayanan memberikan pengaruh yang nyata terhadap indikator harga. Faktor yang memberikan korelasi terbesar pada indikator harga adalah faktor bukti fisik yaitu sebesar 0,620, artinya nasabah merasa puas karena adanya tiga tipe angsuran yang membantu kemampuan pembayaran dan bunga angsuran tidak memberatkan dalam pembayaran serta mendapatkan pelayanan yang sopan dari karyawan. Secara umum kualitas pelayanan memberikan hubungan yang baik terhadap kepuasan nasabah dalam halnya dimensi harga.

Tabel 12. Uji Signifikansi Nilai Korelasi FaktorFaktor Kualitas Pelayanan dengan Dimensi Biaya

\begin{tabular}{|c|c|c|c|c|}
\hline \multicolumn{3}{|c|}{ Hubungan } & Nilai & $p$-value \\
\hline $\begin{array}{l}\text { Perhatian dan } \\
\text { Kompetensi }\end{array}$ & $\rightarrow$ & Biaya & 0,347 & 0,00 \\
\hline $\begin{array}{l}\text { Daya Tanggap } \\
\text { dan Kepastian }\end{array}$ & $\rightarrow$ & Biaya & 0 & 0 \\
\hline 3ukti Fisik & $\rightarrow$ & Biaya & 0,624 & 0,00 \\
\hline
\end{tabular}

Sumber: Data primer yang diolah (2016)

Hasil uji signifikansi untuk nilai korelasi pada Tabel 12 menunjukkan bahwa ketiga faktor kualitas pelayanan memiliki korelasi yang signifikan dengan indikator biaya. Artinya setiap faktor kualitas pelayanan memberikan pengaruh yang nyata terhadap indikator biaya. Faktor yang memberikan korelasi terbesar pada indikator biaya adalah faktor bukti fisik yaitu sebesar 0,624 , artinya nasabah merasa puas karena nasabah melakukan transaksi dengan karyawan yang berpenampilan bersih dan rapi dan juga nasabah tidak harus ke kantor dalam melakukan transaksi (menerima, membayar, dan menabung). Secara umum kualitas pelayanan memberikan hubungan yang baik terhadap kepuasan nasabah dalam halnya dimensi biaya. 


\section{KESIMPULAN}

Hasil penelitian yang dilakukan di Koperasi Arry Sedana Artha menunjukkan bahwa terdapat tiga faktor yang memengaruhi kualitas pelayanan. Faktor-faktor tersebut adalah perhatian dan kompetensi, daya tanggap dan kepastian, dan bukti fisik. Tiga faktor ini mampu menerangkan keragaman kualitas pelayanan sebesar $71,631 \%$, dan $28,369 \%$ diterangkan oleh faktor-faktor lain. Faktor yang dominan memengaruhi kualitas pelayanan adalah faktor perhatian dan kompetensi dengan nilai akar ciri 5,539 dan persentase variansi 46,156\%.

Hasil analisis korelasi kanonik untuk faktorfaktor yang memengaruhi kualitas pelayanan memiliki keeratan hubungan yang nyata dengan kepuasan nasabah di Koperasi Arry Sedana Artha yaitu sebesar 0,869 .

\section{DAFTAR PUSTAKA}

Hair, J., Anderson, R., Tatham, R., \& Black, W. (2010). Multivariate Data Analysis With Reading, Seventh Edition. New Jersey: Prentice Hall International Edition.

Kotler, P. (2005). Manajemen Pemasaran. Jakarta: PT. Intan Sejati Klaten.

Parasuraman, A., Zaithaml, V. A., \& Berry, L. L. (2002). Delivering Quality Service. New York: Mc Milan.

Zeithaml, V. A., \& Bitner, Mary jo. (2003). Service Marketing. New York: Mc GrawHill Companies. 